\title{
Dietary guidelines and food nutrient intakes in Portugal
}

\author{
Pedro Graça \\ Instituto Superior de Ciências da Nutrição e Alimentação da Universidade do Porto, \\ Rua Dr. Roberto Frias 4200, Porto, Portugal
}

\begin{abstract}
The average intakes of nutrients by a group of 489 adult Portuguese ( $\geq 40$ years) living in a metropolitan area of Northern Portugal were studied using a food frequency questionnaire, and used to compare with the most recent recommendations for the same population by the National Council of Food and Nutrition. The data suggested a relative concordance between consumption levels and nutritional goals, however we found differences between subgroups of the population. Higher intakes of total fat and saturated fat, and lower intakes of fibre/energy and carbohydrates were shared by younger people (40-55 years), and higher intakes of total fat, saturated fat, fibre/ energy, protein and carbohydrates and lower intakes of alcohol by women. Nutrients have been analysed in terms of the percentage contribution to total energy intake, but as alcohol is energy dense, its consumption can decrease the proportion of the energy intake from nutrients other than alcohol, and some caution must be taken in interpreting these results.
\end{abstract}

Dietary guidelines: Nutrient intakes: Nutritional policy

Nutrition and public health programmes have not been generally carried out in the last few years in Portugal. The only national nutrition education campaign dates from 1979 ('Knowing how to eat is knowing how to live'), and was divided into three areas: the Awareness Project, the Schools Project and the Regions Project. This campaign followed some studies on Food Balance Sheets and surveys of families' income and expenses carried out in 1973-4 (Brito, 1981). These studies suggested the need to increase the consumption of milk and dairy products, eggs, fish, fruit and vegetables (Gonçalves, 1978). The research studies also indicated the need to maintain the consumption levels of meat, olive oil and butter, whilst reducing all the other fat types, and the need to reduce drastically the consumption of sugar. The consumption of cereals and legumes should be either maintained or increased.

In order to achieve these objectives, a 'food wheel' was devised and was widely disseminated, remaining one of the main methodologies used for nutrition education. The following approximate proportions of food weight were defined for five groups of the food wheel and their respective area: $43 \%$ for vegetables and fruit, $30 \%$ for cereals and cereal products, legumes and potatoes, $14 \%$ for milk and dairy products, $10 \%$ for meat, fish or eggs, $3 \%$ for oils and fats.

More recently, some initiatives have targeted local areas, such as the 'CINDI' Project (1987-93), which aimed to modify food habits in the area of Satúbal (South of Lisbon) via multidisciplinary actions organized in close collaboration with the National Preventive Cardiology Institute and the Ministry of Health. Another example of this type of initiative is the 'Eating better in Oporto! - Reacquiring Quality' (1994-6) project, which was meant to improve the quality of food in restaurants and food outlets in the city of Oporto in collaboration with the University of Oporto, the Portuguese Society of Nutrition and Food Sciences (SPCNA) and Oporto County Council. The 'Bread of Health' project (Algarve region), organized by the Ministry of Health (1990-98), is yet another example.

Additionally, other projects were also devised to target the country as a whole but with specific objectives, as in the case of 'Training Courses for Food Handling Professionals in Schools' organized by the Department of Primary Education - Ministry of Education (1995-8), and the Forum of Food Education Projects organized twice $(1994,1995)$ by the National Council of Food and Nutrition (CNAN) - scientific meetings where small projects of nutrition and public health were discussed (CNAN, 1994).

In 1982 the Centre of Nutrition Studies (CEN), which belongs to the National Institute of Health, issued some recommendations for the Portuguese through the Food Education Commission, which were brought up to date in 1997 by the National Council of Food and Nutrition (CNAN) via the Food Education Commission (CNAN, 1997). The latter published reference values for the Portuguese adult population, a document to be used by Health Professionals (Table 1). 
Table 1. Recommendations for the Portuguese Adult Population by the National Council of Food and Nutrition (CNAN) and translated dietary recommendations

1. Total carbohydrates should contribute a total daily energy value of $50-70 \%$;

2. Fibre intake should vary between 27 and $40 \mathrm{~g} / \mathrm{d}$;

3. Total lipids consumption $\leq 30 \%$ of total daily energy;

4. Consumption of saturated fatty acids $<10 \%$ of total daily energy;

5. Cholesterol consumption $<300 \mathrm{mg} / \mathrm{d}$;

6. Total saccharose $<20-30 \mathrm{~g} / \mathrm{d}$;

7. Salt $<6 \mathrm{~g} / \mathrm{d}$;

8. Reduce alcohol consumption;

9. Calcium - total daily intake of $800 \mathrm{mg}$.

1. Breast-feeding in the first months of a baby's life, especially during the first six months;

2. Adequate consumption of cereals and cereal products;

3. Increase of the consumption of vegetable products and fresh fruit;

4. Reduction of the consumption of fats, especially solid and overheated fats; preference given to olive-oil consumption;

5. Increase of fish consumption;

6. Reduction of sugar and sugar-like products consumption;

7. Reduction of salt consumption;

8. Moderate consumption of alcoholic drinks. Pregnant women, children and those younger than 17 should not drink alcohol.

9. Adequate consumption of milk and dairy products;

10. Weight control kept through a balanced diet and physical activity;

11. A balanced meal first thing in the morning.

The studies on food or nutrients intake in representative healthy groups are virtually non-existent in Portugal. In order to obtain information on the Portuguese population's dietary habits, we have to focus on the 'Epicardis' research study, which started in 1995 (Barros et al. 1997) $\dagger$. It is a community-based case-control study, which uses the catchment area of S. João's Hospital as geographical reference: that is, essentially, the Greater Oporto area. It was designed to investigate risk factors for acute myocardial infarction in general and to estimate the association of the disease with specific dietary factors in particular. Although the sample was not representative of the Portuguese population, we used the data related to community controls of the study since the methodology for gathering, selecting and treating the information is reliable as far as we are concerned and meets the objectives proposed to some extent. Furthermore, the data relate to a very recent period, in sharp contrast with the last national survey on food, which dates back to 1980.

\section{Methods}

The 489 participants were selected according to their age group - that is, adult individuals aged 40 or more - from both sexes, and living in the geographical catchment area of S. João's Hospital. In practice, the individuals were selected at random, through the random digit dialling method (Hartge et al. 1984), since this technique conceives residences as sampling units, and a second simple random method

$\dagger$ Founded by JNICT, Project No. 2/2.1/SAU/1332/95 followed in order to select the participant in each dwelling. The telephone numbers not answered after four trials in different days and at different times were ignored. All the individuals that refused to participate were excluded, as well as individuals aged 65 or more who obtained a score of fewer than 24 points in the 'Mini-mental state examination' according to Folstein (Folstein et al. 1975). The sampling of participants was compared with the age and sex distribution of the general population of Oporto (aged 40 or more) and a similar distribution was observed (Barros et al. 1997). The demographic, social and health characteristics of the individuals selected for the study were also compared, including the ones that accepted and those who refused. No significant differences were found in relation to the assessed characteristics (sex, age, marital status, education, professional status, present occupation, smoking habits, alcohol habits, chronic diseases, measurement of blood pressure, clinical analyses and medical appointments in the last year) (Barros et al. 1997).

Food habits were studied through the quantitative and qualitative assessment of food intakes. Accordingly, a semiquantitative survey was linked to the frequency of food ingested in the year prior to the interview (FFQ) and including, for instance, data gathered concerning some food habits and behaviours (such as the frequency of different cooking processes and fat types used, and the number of daily meals). The FFQ included 82 food items, or food groups with similar nutritive characteristics, a closed section with nine frequency categories varying from 'never or less than once a month' to 'six times a day or more', and predetermined average portions. The selection of the list of foods was based on both the Portuguese Foods Composition Table and data of former studies (Ferreira \& Graça, 1985). The choice of average portions was based on previous works (Lopes et al. 1994) and research studies that used similar semi-quantitative surveys applied to other populations (Amaral et al. 1993), which were subsequently adapted to the presumed consumption levels of the Portuguese population. The consumption frequencies are indicated in relation to the average portions for each food item illustrated by a photographic manual comprising 90 colour photos, which work as a visual aide to the individuals investigated, allowing them to choose multiples or sub-multiples of average quantity.

The consumption frequency is transformed into average daily values for the calculation in grams of each food product or food group. This frequency is subsequently multiplied by the predetermined quantity for each portion, in grams. For food products only consumed in certain periods, and when indicated by the people surveyed, the value found is multiplied by a seasonal variation factor of 0.25 (the average seasonal period comprising three months). The products ingested with a frequency of the type 'never or less than once a month' are not contemplated for the calculation of nutrient intakes. The daily average quantities are converted into nutrients through the 'Food Processor Plus' program, version 5.0 (ESHA Research, USA). The nutritional composition of typically Portuguese dishes or food products was added to their original basis using data from the Portuguese Food Composition Table (Ferreira \& Graça, 1985) and from some works published in Portuguese publications (Amaral 
Table 2. Mean intakes of energy and selected nutrients in a sample of Portuguese subjects and also classified according to age and sex

\begin{tabular}{|c|c|c|c|c|c|c|c|c|c|c|}
\hline & & & \multicolumn{4}{|c|}{ Males } & \multicolumn{4}{|c|}{ Females } \\
\hline & Mean & SD & Mean & SD & Mean & SD & Mean & SD & Mean & SD \\
\hline Energy (MJ) & 9.7 & 2.8 & 11.5 & 3.2 & $10 \cdot 3$ & 2.5 & 9.2 & $2 \cdot 2$ & 8.4 & 2.4 \\
\hline Total fat (\%energy) & 28.5 & 5.0 & 28.2 & 4.7 & $26 \cdot 7$ & $5 \cdot 0$ & 30.9 & $4 \cdot 4$ & $29 \cdot 1$ & $5 \cdot 2$ \\
\hline PUFA (\%energy) & 4.9 & $1 \cdot 1$ & 4.9 & 1.2 & 4.7 & $1 \cdot 1$ & 4.9 & 1.0 & 4.9 & 1.2 \\
\hline Protein (\%energy) & $18 \cdot 0$ & 2.8 & $17 \cdot 1$ & $2 \cdot 7$ & $16 \cdot 8$ & $2 \cdot 6$ & $19 \cdot 2$ & $2 \cdot 7$ & $18 \cdot 6$ & 2.6 \\
\hline Carbohydrate (\%energy) & $49 \cdot 1$ & 7.5 & $45 \cdot 3$ & 6.8 & 47.9 & 7.8 & 49.5 & $6 \cdot 4$ & $52 \cdot 3$ & $7 \cdot 1$ \\
\hline Alcohol (\%energy) & $5 \cdot 7$ & $7 \cdot 2$ & $10 \cdot 8$ & $7 \cdot 7$ & 9.9 & 8.5 & $2 \cdot 3$ & 3.5 & 1.9 & 3.5 \\
\hline Fibre $(\mathrm{g})$ & $26 \cdot 3$ & $9 \cdot 3$ & $26 \cdot 3$ & 8.2 & $27 \cdot 2$ & 9.9 & $25 \cdot 9$ & 8.7 & 25.9 & 9.9 \\
\hline Fibre/MJ energy (g/MJ) & 2.8 & 0.9 & 2.4 & 0.7 & 2.7 & 0.8 & 2.8 & 0.7 & 3.2 & 1.1 \\
\hline Vitamin C (mg) & 139.0 & 63.4 & 135.7 & $60 \cdot 7$ & $130 \cdot 1$ & 63.2 & $156 \cdot 4$ & 64.4 & $132 \cdot 3$ & $62 \cdot 3$ \\
\hline
\end{tabular}

SFA = saturated fatty acids; MUFA = monounsaturated fatty acids; PUFA = polyunsaturated fatty acids; RE = retinol equivalents.

et al. 1989, Mano et al. 1989, Batista \& Bandarra, 1993). The food survey used and the structuring of the data base for the calculation of nutrients was based on an adaptation of an established method (Willett, 1991).

\section{Results}

The average intakes of nutrients were compared with the most recent recommendations for the Portuguese population (Table 2). No food ingestion data are included in this study as a result of conversion problems with the program. In order to reduce these problems, we have included data on the ingestion of both Vitamin $\mathrm{C}$ and carotenoids, which supply direct information on fruit and vegetables consumption (CNAN, 1997).

Differences between sex and age groups show higher average daily intakes of saturated fat (SFA) and total fat by both the youngest age groups and women. There seem to be no substantial differences in regards to intakes of monounsaturated and polyunsaturated fatty acids. There seems to be a relatively similar consumption pattern with higher intakes of protein, fibre and carbohydrates among women.
The youngest subjects also seem to have higher daily intakes of protein and carbohydrates. Alcohol consumption inverts this tendency for a higher consumption of macronutrients by women, since men are the predominant alcohol consumers.

The average daily nutrition intakes of people on the lowest and highest quartiles of total fat consumption show very similar energy intakes and very different alcohol intakes. Additionally, fibre and carbohydrates intakes seem higher in relation to low-fat consumers, whilst the consumption of the several fat types and protein increases for high-fat consumers (Tables 3 and 4).

Due to the lack of available information on the consumption of food products by the population surveyed till this moment, we have used information published by the National Statistics Institute (INE) regarding the Portuguese Food Balance Sheets. According to the INE, the available data reflect the changes that have occurred in the last few decades (1970-92) in terms of the consumption of fat (29 to $35 \%$ energy), protein (11 to $13 \%$ energy) and carbohydrates (59 to $53 \%$ energy) in the Portuguese population (INE, 1994).

Table 3. Daily nutrient intakes of Portuguese having low and high fat intakes (\%energy)

\begin{tabular}{|c|c|c|c|c|c|c|}
\hline & \multicolumn{3}{|c|}{$\begin{array}{c}\text { Low } \\
\text { (cut-off }=25 \% \text { energy) }\end{array}$} & \multicolumn{3}{|c|}{$\begin{array}{c}\text { High } \\
\text { (cut-off }>32 \% \text { energy) }\end{array}$} \\
\hline & Mean & SD & Median & Mean & SD & Median \\
\hline Energy (MJ) & 9.7 & 2.9 & 9.5 & 9.8 & 2.7 & $9 \cdot 3$ \\
\hline Protein (\%energy) & $16 \cdot 6$ & $2 \cdot 6$ & 16 & $19 \cdot 2$ & 2.9 & 19 \\
\hline Carbohydrate (\%energy) & $52 \cdot 7$ & 8.9 & 54 & 44.8 & 5.5 & 45 \\
\hline Alcohol (\%energy) & $10 \cdot 1$ & $9 \cdot 4$ & 9 & 2.8 & 4.4 & 1 \\
\hline SFA (\%energy) & 6.4 & 1.2 & 6 & 11.4 & $2 \cdot 1$ & 11 \\
\hline MUFA (\%energy) & 9.7 & 1.3 & 10 & 14.9 & 1.9 & 14.5 \\
\hline PUFA (\%energy) & $4 \cdot 1$ & 0.8 & 4 & $5 \cdot 6$ & 1.2 & 5 \\
\hline Fibre (g) & 28.7 & $10 \cdot 8$ & $27 \cdot 4$ & 24.9 & 8.9 & $24 \cdot 3$ \\
\hline Fibre/MJ energy ( $g / M J)$ & 3.0 & $1 \cdot 1$ & 2.9 & 2.6 & $0 \cdot 8$ & 2.4 \\
\hline Vitamin C $(\mathrm{mg})$ & $134 \cdot 7$ & 68.3 & 120 & $144 \cdot 2$ & 68.5 & 132.5 \\
\hline Carotenoids (RE) & $1296 \cdot 8$ & 840 & 1190 & 1373.8 & $790 \cdot 1$ & 1258 \\
\hline
\end{tabular}

$\mathrm{SFA}=$ saturated fatty acids; MUFA = monounsaturated fatty acids; PUFA = polyunsaturated fatty acids; $\mathrm{RE}=$ retinol equivalents. 
Table 4. Daily nutrient intakes of Portuguese consuming low and high levels of SFA (\%energy)

\begin{tabular}{|c|c|c|c|c|c|c|}
\hline & \multicolumn{3}{|c|}{$\begin{array}{c}\text { Low } \\
\text { (cut-off }=6 \% \text { energy) }\end{array}$} & \multicolumn{3}{|c|}{$\begin{array}{c}\text { High } \\
\text { (cut-off }>10 \% \text { energy) }\end{array}$} \\
\hline & Mean & SD & Median & Mean & SD & Median \\
\hline Energy (MJ) & 9.5 & $2 \cdot 7$ & $9 \cdot 2$ & $10 \cdot 0$ & 2.9 & $9 \cdot 7$ \\
\hline Protein (\%energy) & 16.5 & $2 \cdot 4$ & 17 & 18.9 & $2 \cdot 8$ & 19 \\
\hline Carbohydrate (\%energy) & $54 \cdot 3$ & $7 \cdot 7$ & 55 & $46 \cdot 8$ & $5 \cdot 8$ & 46 \\
\hline Alcohol (\%energy) & $4 \cdot 3$ & $5 \cdot 1$ & 4 & $1 \cdot 8$ & $3 \cdot 1$ & 0 \\
\hline Total fat (\%energy) & 21.9 & $2 \cdot 9$ & 22 & $33 \cdot 2$ & $3 \cdot 8$ & 33 \\
\hline MUFA (\%energy) & 9.8 & 1.9 & 10 & $13 \cdot 9$ & $2 \cdot 2$ & 14 \\
\hline PUFA (\%energy) & 4.3 & 0.9 & 4 & $5 \cdot 1$ & 1.2 & 5 \\
\hline Fibre (g) & $29 \cdot 4$ & $11 \cdot 2$ & 28.5 & 24.5 & $8 \cdot 3$ & 23 \\
\hline Fibre/MJ energy (g/MJ) & $3 \cdot 1$ & 0.9 & $2 \cdot 9$ & 2.5 & 0.7 & $2 \cdot 4$ \\
\hline Vitamin C (mg) & 133.5 & $76 \cdot 3$ & 120 & $145 \cdot 5$ & 64.9 & 134 \\
\hline Carotenoids (RE) & $1426 \cdot 7$ & $882 \cdot 3$ & 1229.5 & $1304 \cdot 1$ & 664.9 & 1224 \\
\hline
\end{tabular}

SFA = saturated fatty acids; MUFA = monounsaturated fatty acids; PUFA = polyunsaturated fatty acids; $\mathrm{RE}=$ retinol equivalents.

\section{Discussion}

The data presented in this paper are based on the daily intakes of a group of people, living in a metropolitan area of Northern Portugal, and do not give a detailed information in relation to the whole population. However, we believe that the information gathered helps to characterize a vast group of the Portuguese population, since the socio-demographic profile of the people surveyed, whilst being similar to that of the Oporto population of the same age group, represents a certain type of population, from an urban area, which characterizes the majority of the Portuguese population today. (Nowadays, the two main metropolitan areas of the country alone represent more than $35 \%$ of the total population (Ferrão, 1996).

However, the fact that there was no one aged less than 40 among the people surveyed restricts the analysis to some extent. From the population observed, we can find significant differences between the two age groups studied in terms of fat intakes. The youngest group, aged between 40-45, reveals a higher total fat consumption (including SFA). Women also had higher total fat intakes (SFA included). Fibre (g/MJ) and carbohydrate intakes (\%energy) are significantly higher among both the oldest populations (those aged 55 or more) and women. As an indirect way of assessing fruit and vegetable consumption, intakes of Vitamin $\mathrm{C}$ and carotenoid suggest that women and younger subjects are the biggest consumers of these products. Thus, the highest quality of fibre intakes by the oldest members of the population probably originates from the consumption of cereals and cereal products, as well as legumes, such as chick-peas, beans, which are inexpensive and accessible products. Alcohol intakes seem very high $(\overline{\mathrm{x}}=5.7 \%$ energy) but vary between the two sexes (five times higher for males). This high quantity of alcohol can alter the proportions of macronutrients, since it also contributes to the total energy consumed, a reason why it should be considered individually. For instance, in the case of high intakes of alcohol, for which men are generally responsible, the ingestion of macronutrients is proportionally lower due to the energy intake from alcohol ingestion. Another question worth considering is the extent to which alcohol intakes are under-reported by women in this type of surveys, due to social and cultural prejudices, and which cannot therefore be quantified at this stage.

Data from an ongoing project, using similar food consumption methodology but with a younger group $(X=20 \cdot 3$ years suggest average intakes of total fat (32\%energy), SFA (10.5\%energy) and protein (19.9\%energy) higher than those observed in our population, which partly confirm our line of thought and lead us to conclude that it is worth devising different strategies for different sex and age groups. This information is also in accordance with the Portuguese Food Balance Sheets that suggest a significant increase in intakes of fat (butter, margarine and oils), dairy products and meat, which do not seem to affect the oldest population as much.

None the less, the data suggest a relative concordance between the Portuguese recommendations and the consumption levels by the present population aged 40 or more. This information may indicate that a substantial change in the youngest generation seems to have occurred as far as nutrients and food consumption are concerned. Moreover, the recent changes in the distribution structure, work schedules, products available to consumers and in the knowledge and ability to prepare meals that are balanced and adapted to people's needs, pose new problems. This is particularly true for those assessing nutrient intakes due to the lack of available data regarding the composition of new products and the great heterogeneity of situations. These problems are also present in food recommendations that tend to be more and more recommendations about food products. Due to the constant innovation in this area, illustrated by the daily emergence of new food products, the recommendations will have to be adapted to this new reality.

\section{References}

Amaral CCF, Sequeira CD \& Camacho MA (1989) Iogurte composição e valor nutritivo de variedades comercializadas em Portugal. Subsídio para a tabela de composição dos alimentos portugueses. Revista Portuguesa de Nutrição 3, 35-52.

Amaral TF, Nogueira C \& Paiva I (1993) Pesos e porções de alimentos. Revista Portuguesa de Nutrição 2, 13-23. 
Barros H, Lopes C \& Hafe P (1997) Risco de Enfarte do Miocárdio: Um estudo Comunitário. Arquivos de Medicina 11, 285-294.

Batista I \& Bandarra NM (1993) Influência de quatro métodos culinários na composição quimica de várias espécies de peixes. Revista Portuguesa de Nutrição 3, 5-14.

Brito MG (1981) A Campanha de Educação Alimentar. Boletim Informativo. Lisboa: Direcção-Geral de Coordenação Comercial.

CNAN (Conselho Nacional de Alimentação e Nutrição, Comissão de Educação Alimentar) (1994) Proceedings of the Ith Forum de Projectos de Educação Alimentar. Lisboa: Conselho Nacional de Alimentação e Nutrição.

CNAN (Conselho Nacional de Alimentação e Nutrição, Comissão de Educação Alimentar) (1997) Recomendações para a Educação Alimentar de População Portuguesa. Revista Portuguesa de Nutrição 2, 5-19.

Ferrão J (1996) Três décadas de consolidação do Portugal demográfico «moderno». In A situação social em Portugal, 19601995, pp 165-190 [A Barreto, editor]. Lisboa: Instituto da Ciências Sociais da Universidade de Lisboa.

Ferreira FAG \& Graça MES (1985) Tabela de composição de alimentos portugueses ( $2{ }^{\mathrm{a}}$ edição). Lisboa: Instituto Nacional de Saúde Dr. Ricardo Jorge.
Folstein MF, Folstein SE \& McHush PR (1975) 'Mini-mental state'. A practical method for grading the cognitive state of patients for the clinician. Journal of Psychological Research $\mathbf{1 2}$ 189-198.

Gonçalves FAA (1978) Política Alimentar e de Nutrição em Portugal. Revista do Centro de Estudos da Nutrição 2, 3-28.

Hartge P, Brinton LA, Rosenthal JF, Cahill JI, Hoover RN \& Waksberg J (1984) Random digit dialing in selecting a population-based control group. American Journal of Epidemiology 120, 825-833.

INE (Instituto Nacional de Estatística) (1994) Balança Alimentar Portuguesa: 1980-92. Lisboa: Instituto Nacional de Estatística.

Lopes C, Fernandes PV \& Barros H (1994) Questionário de frequência alimentar - Efeito da extensão da lista de alimentos na classificação dos inquiridos. Arquivos de Medicina 8, 291294.

Mano ML, Meister MC \& Fontes MR (1989) Composição de alguns alimentos cozinhados. Alguns produtos servidos em 'snack-bares'. Revista Portuguesa de Nutrição 4, 19-24.

Willett WC (1991) Food frequency methods. In Nutritional Epidemiology, pp 60-90 [WC Willett, editor]. Oxford: Oxford University Press. 